\title{
Bilişim Sektöründe Girişimcilik, Balıkesir Üniversitesi Bilgisayar Mühendisliği Öğrencilerinin Girişimcilik Eğilim Ve Niyetleri Üzerine Bir Araştırma*
}

\author{
Özlem KUVAT**
}

\begin{abstract}
$\ddot{O} Z$
Son yillarda bilişim teknolojilerinin kullanımındaki gelişmeler ile bu sektörde çalışan nitelikli bireylerin yetişstirilmesi gittikçe önem kazanmaktadır. Ayrıca sektörün bu ihtiyacına yönelik girişimci niteliklerini taşlyan ve kendi işini kurma düşüncesindeki bireylerin bu özelliklerinin de belirlenip değerlendirilmesi bilişim alanı için önemlidir. Bilgisayar Mühendisliği öğrencileri iş dünyasındaki kendi işini kuran kişilere yönelik talebin karşılanması için özellikle bilişim teknolojileri sektöründe potansiyel girişimci adaylarıdır. Bu çalışma Balıkesir Üniversitesi Bilgisayar Mühendisliği ögrencilerinin girişimcilik eğilimlerinin ve niyetlerinin sosyo-demografik özellikleriyle birlikte değerlendirilmesi amacıyla gerçekleştirilmiştir. Çalışmada öğrencilerin sosyodemografik özellikleri, girişimcilik eğilimi ve niyetleri ile ilgili özellikleri taşıma durumlarına iliş̧kin veriler, öğrencilere uygulanan anketler yoluyla toplanmıştır. Verilerin değerlendirilmesinde frekanslar belirlenmis ve ögrencilerin kariyer planlarıyla diğer değişkenler arasındaki ilişkilerinin araştıııldı̆̆ (bilgirişim) desteklenmesine ve ihtiyaçların giderilmesine yönelik öneriler sunulmuştur.
\end{abstract}

Anahtar Kelimeler: Girişimcilik, Girişimcilik Eğilimi ve Niyeti, Bilişim Teknolojileri (BT/BİT) Sektörü, Bilgirişim.

JEL Sinıflandırması: C14, M13, 21

\section{Entrepreneurship In The Information And Communication Technology (Ict) Sector, A Research On Entrepreneurship Tendencies And Intentions Of Balıkesir University Computer Engineering Students}

\begin{abstract}
In recent years, with the developments in the use of information technologies, the training of qualified individuals working in this sector has become increasingly important. It is also important for the field of information to determine and evaluate these characteristics of the individuals who have entrepreneurial characteristics towards this need of the sector and who are considering to establish their own business. It is also important for the field of knowledge to determine and evaluate these characteristics of the individuals who have entrepreneurial characteristics towards this need of the sector and who are considering to establish their own business. Computer Engineering students are potential entrepreneur candidates, especially in the information and communication technology (ICT) industry, to meet the demands of their business people in the business world. This study was carried out in order to evaluate the entrepreneurship tendencies of Ballkesir University Computer Engineering students with their socio-demographic characteristics. In the study, the data were collected through questionnaires applied to the students and in these surveys, students were asked about the socio-demographic characteristics and
\end{abstract}

\footnotetext{
* Bu çalışma sözlü olarak 14-17 Temmuz 2017 tarihlerinde Balıkesir'de düzenlenen 8. Uluslararası Girişimcilik Kongresi (ICE 2017)'nde sunulmuş, geliştirilerek makale formatına getirilmiştir.

** Dr. Ögr. Üyesi Balıkesir Üniversitesi İ̈BF İşletme Bölümü,. email:ohasgul@ balikesir.edu.tr

(Makale Gönderim Tarihi:09.11.2017 / Yayına Kabul Tarihi:28.12.2018)
}

Doi Number: 10.18657/yonveek.350282 
characteristics of entrepreneurship tendency and intention. In the evaluation of the data, frequencies were determined and statistical analyzes were carried out to investigate the relationship between students' career plans and other variables. As a result of, suggestions have been presented in order to support entrepreneurship in the ICT sector.

Key Words: Entrepreneurship, Entrepreneurship Tendency and Intention, Information and Communication Technology (ICT) Sector, Computer-Entrepreneurship.

JEL Classification: C14, M13, 121

\section{GíRIŞ}

Bilişim sektörü bileşenlerinin son yıllarda artan kullanımıyla beraber yaşanan gelişmeler sektörde artan taleplerle beraber hem nitelikli işgücü, hem de kendi işini kurabilecek girişimcilere yönelik ihtiyaca yol açmıştır. Dünyada yaşanan teknolojik ilerlemelerin yansımasıyla Türkiye'de de iş hacminin büyümesi girişimcilere çeşitli firsatlar sunmaktadır. $\mathrm{Bu}$ firsatların değerlendirilmesinde girişimci özelliğine sahip olan ve aynı anda sektörün içinde bulunan kişiler ayrıca avantajlı konumda olan kişilerdir. Bilgisayar Mühendisleri de sektör içinde yüksek düzeyde çalışma oranları olan kişilerdir ve girişimci niteliklerine sahip olmaları ve kendilerini bu konuda hazırlamaları sektör içerisinde kendi işlerine sahip olmaları için adım attırıcı özelliklerden olacaktır. Ayrıca sektörün bu ihtiyacına yönelik girişimci niteliklerini taşıyan ve kendi işini kurma düşüncesindeki bireylerin bu özelliklerinin belirlenip değerlendirilmesi ve ihtiyaçlarının giderilmesi bilişim alanı için önemlidir.

Gelecekte bilişim sektöründe çalışma potansiyeline sahip olan Bilgisayar Mühendisliği öğrencilerinin de girişimci olmaya yatkınlıklarının belirlenebilmesi de onların başarılarını arttırmaya yönelik desteklerin sağlanabilmesi için önemli olacaktır. Üniversite öğrencilerinin girişimcilik eğilim ve niyetlerinin belirlenmesi konusunda literatürde çok sayıda çalışma bulunmaktadır. Buna karşın özellikle bilişim sektörü girişimciliği ve bilgisayar mühendisliği öğrencilerinin eğilim ve niyetlerinin değerlendirilmesi konusundaki eksiklikler bu çalışmanın konusunun belirlenmesinde etkili olmuştur. Çalışmanın amacı Bilgisayar Mühendisliği öğrencilerinin girişimci olma eğilimlerinin ve niyetlerinin araştırılmasıdır. Uygulama Balıkesir Üniversitesi Bilgisayar Mühendisliği öğrencilerinin katılımıyla gerçekleştirilmiştir. Veri toplama aşamasında anket yöntemi kullanılmıştır. Çalışma üç bölümden oluşmaktadır. Çalışmanın birinci bölümünde bilişim sektöründe girişimcilere duyulan ihtiyacın ve girişimci özelliklerinin tanıtıldığı literatür incelenmiştir. İkinci bölümde kullanılan yöntem ve veri tanitılmış, bulgulara yer verilmiştir. Üçüncü bölümde uygulamaya dair sonuç ve öneriler yer almaktadır.

\section{GIRISSIMCİ ÖZELLIKKLERI}

Girişimcilik, bir ülke ekonomisinde yenilik (inovasyon) yapma, rekabet yaratma, istihdam sağlama olanaklarını arttıran ve böylece ekonomik zenginlik ve harcama gücüne katkıda bulunan bir faaliyettir (Gurel vd., 2010). Girişimcilik aynı zamanda farklı anlamları içinde barındıran çok boyutlu ve karmaşık bir olgudur ve çeşitli araştırmacılar farklı faktörler çerçevesinde bu kavramı değerlendirip yorumlamaktadırlar (Uygun vd., 2012). Girişimciler de yaratıcı düşünceye sahip olarak işlerinde başarıya ulaşan, yüksek gelir elde edecek orijinal 
düşüncelerle yeni fikirler bulan ve yeni firsatlar keşfeden kişilerdir (Arslantaş, 2001). Girişimcilerin sahip oldukları bu ve benzeri özellikler de literatürde pek çok çalışmanın konusunu oluşturmuştur.

\section{A. Girişimcilik Ĕğilimi ve Niyeti}

Üniversite öğrencilerinin girişimcilik eğilimlerinin ve niyetlerinin değerlendirilmesi bu konuda yapılan çalışmaların bir kısmının amacını oluşturmaktadır. Üniversite öğrencileri de girişimcilik potansiyeline sahip kişiler olarak görülmektedir ve pek çok çalışmada üniversite öğrencilerinin girişimcilik eğilimleri ve niyetleri yapılan anketlerin sonucuna göre belirlenmeye çalışılmıştır. $\mathrm{Bu}$ çalışmalarda yaş, cinsiyet, eğitim, ailenin gelir durumu gibi değişkenlerin ilişkisi ve girişimcilik eğilimi ile niyetlerinin ölçümü çeşitli görüşlerin ve özelliklerin yer aldığı ifadeler ile yapılmaktadır. Bazı çalışmalarda bu görüşler faktörlere ayrılmış, ölçekler oluşturulmuştur.

Girişimcilik niyeti, girişimci olmanın istenebilirliği ve girişimciliğin yapılabilirliği ile ilgili algıdan ve bununla ilişkili firsatlardan yararlanabilme eğiliminden gelişmektedir (İrmiş ve Barutçu, 2012). Girişimcilik niyetinin ölçümü kişilerin iş kurma niyetlerinin olup olmadığına ilişkin sorulan sorulara verilen yanıtların değerlendirilmesiyle yapılmaktadır (Gurel vd., 2010).

\section{B. Demografik özellikler}

Üniversite öğrencilerinin girişimcilik eğilim ve niyetlerini saptamaya yönelik olarak yapılan pek çok araştırmada girişimcilik eğiliminin cinsiyet, yaş, rol modeller, aile özgeçmişi, deneyimler ve eğitim gibi demografik faktörlerle bağlantılı olduğu belirlenmiştir (Solmaz vd., 2014; Uygun vd., 2012).

Girişimcilik eğilimi ile cinsiyetin ilişkisinin değerlendirildiği bazı çalışmalarda erkekler kadınlara göre daha eğilimli bulunmuştur (İrmiş ve Barutçu, 2012; Uygun vd., 2012; Shekhawat vd., 2012). Buna karşın bağımsızlık, içsel denetim odağ 1 ve yaratıcılık gibi bazı girişimcilik özellikleri dikkate alındığında kadınlar girişimciliğe erkeklere göre daha eğilimli bulunmuştur (Özdemir, 2015). Girişimcilik niyeti ile cinsiyetin ilişkisinin değerlendirildiği çalışmalar da bulunmaktadır. Örneğin Sánchez ve Orazio (2012) çalışmasında girişimcilik niyeti ile girişimci öz yeterliliği, risk alma eğilimi ve proaktifliğin cinsiyet ile ilişkisini araştırmış, cinsiyetin girişimcilik niyeti üzerinde etkili olduğu sonucuna ulaşmışlardır. Çalışma sonuçlarına göre erkekler kendilerini daha etkin ve yeni bir girişim için yönelimli hissetmektedirler (Sánchez ve Orazio, 2012). Bazı çalışmalarda ise girişimcilik eğiliminin ya da niyetinin cinsiyet ile ilişkisi anlamlı bulunamamıştır (Abbas, 2013; Öztürk vd., 2014).

Girişimcilik eğilimi ve niyeti üzerinde farklı demografik değişkenlerin de etkisi araştırma konusudur. Aile yapısı, aile desteği, yaş, eğitim, daha önce çalışma durumu gibi değişkenler etkili olabilmektedir. Örneğin, Denanyoh vd. (2015), çalışmasına göre, eğitim, aile ve yapısal desteklerin girişimcilik niyeti üzerinde anlamlı ilişkileri bulunmaktadır (Denanyoh, 2015). Turker ve Selçuk (2009) çalışmalarında üniversite öğrencilerinin girişimcilik niyetleri ile eğitimsel ve yapısal desteklerin ilişkili olduğu sonucuna varmışlardır (Turker ve Selçuk, 2009). Uygun vd. (2012)'nin elde ettiği sonuçlara göre, Aksaray Üniversitesinde 
okuyan öğrenciler içinde Mühendislik Fakültesi okuyanlar diğerlerine göre kendi işini kurma konusunda daha eğilimlidirler (Uygun vd., 2012).

\section{Kişilik özellikleri}

Girişimcilik eğilimini etkileyen önemli bileşenlerden biri doğuştan var olan ve sonradan edinilen kişilik özellikleridir (Sarıtaş ve Duran, 2017). Kişilik özelliklerinin de girişimcilik eğilimi ve girişimcilik niyeti üzerindeki etkisi bu konunun inceleme alanlarındandır. Girişimcilerin kişilik özellikleri çok farklı ifadelerle ortaya konmaya çalışılsa da literatürde çoğunlukla yaygın olarak kabul görmüş bazı kavramlarla ifade edilmektedir. Bağımsız çalışma, risk alabilme, belirsizliğe olan tahammül, başarı ihtiyacı, kendine güven, yenilikçilik ile otokontrol ve iyimserlik bu özelliklerdendir (Başer ve Büber, 2012).

Girişimcilik eğilimi için literatürde yaygın olarak, bu özelliklerin faktörler şeklinde değerlendirildiği çok sorulu anketler kullanılmıştır. Koh (1996)'un, Hong Kong’ta MBA öğrencileri üzerinde yaptığı çalışmada özdeğerlendirme ölçeğine dayanan başarı ihtiyacı duyma, kontrol odağı, risk alma eğilimi, belirsizliğe karşı toleranslı olma, özgüven ve yenilikçilik kavramları için 36 yapı ve 6 değişkeni kullanarak logit model kurmuştur. Yenilikçilik, belirsizliğe karşı tolerans ve risk alma eğilimi değişkenlerinin girişimcilik eğilimi üzerindeki etkisi anlamlı bulunmuştur (Koh, 1996). Uygun vd. (2012) azim, başarı motivasyonu, özerklik, merak ve öğrenme isteği, özgüven, risk alma eğilimi ile yenilikçilik boyutlarından oluşan 40 madde ile kişilik ölçeği oluşturmuş, girişimcilik eğilimi ile kişilik özelliklerinden risk alma ve özgüven arasında anlamlı ilişki olduğu sonucuna varmıştır. $\mathrm{Bu}$ kişilik özellikleri arttıkça genç girişimci adayların girişimci olma eğiliminin artmakta olduğuna ilişkin bulgular elde etmişlerdir (Uygun vd., 2012). Sakarya Üniversitesi ve Abant İzzet Baysal Üniversitesi'nde gerçekleştirilen çalışmada 6 kişilik boyutu için elde edilen sonuçlara göre, kadınlar erkeklere göre daha yüksek aritmetik ortalama değerlerine sahiptir (Solmaz vd. 2012).

Girişimcilik niyeti için öğrencilerin bakış açısı dikkate alındığında bir iş kurmak karmaşık bir karardır ve yüksek belirsizlik ile risk içermektedir. Öğrencilerin niyetini içsel (yüksek motivasyon ve kişisel özellikler..) ve dişsal faktörler (dış çevre) etkileyebilmektedir (Shekhawat vd., 2012). Başol vd. (2011) kişiliğin girişimcilik niyeti üzerine etkisini araştırdığı çalışmasında nörotisizm, dışa dönüklük ve psikotisizm boyutlarıyla değerlendirdiği Eysenck kişilik anketiyle birlikte girişimci öz yeterlilik anketini kullanmıştır. Girişimci özyeterlilikleri açısından en önemli kişilik tipinin dışa dönük kişilik tipi olduğu sonucunu elde etmiştir (Başol, 2011).

\section{BILIŞSIM SEKTÖRÜNDE GIRISŞIMCİLIK}

Dünyada 20. Yüzyılın sonlarına kadar bilgi işlem sürecinin hızı ve önemi yeterince anlaşılmamış olsa da günümüzde bilginin el altında tutulması düşünülemez. İş dünyasını etkileyen üç büyük değişim bu süreçte etkili olmuştur. Bunlar küresel ekonominin doğuşu, endüstriyel ekonomilerin dönüşümü ve girişimlerdeki değişim süreçleridir Bu değişim ve dönüşümler sonucunda bilgi ve bilişim devrimi başlamıştır ve bu süreç hala devam etmektedir (Karahoca ve 
Karahoca,1998: 3). Türkiye'nin bilgi toplumuna dönüşümü 2013 yılından bu yana yürütülen e-Dönüşüm Türkiye Projesi kapsamında hız kazanmıştır. 2006-2010 dönemi boyunca da bilgi toplumu stratejisi ve eylem planı uygulanmıştır. Türkiye'de 2013 y1lında Bilişim teknolojisi (Bilişim ve İletişim Teknolojisi, BT, BİT, ICT) sektörünün toplam ihracat1, ihracat yapan öncelikli sektörlerden biri olarak 1,3 milyar TL miktarında gerçekleşmiştir. İhracatın 113 milyon TL'si donanım, 721 milyon TL si yazılım iken 156 milyon TL si hizmet alanındadır. 2013 yılında istihdam edilenlerin sayısı 254 bin kişidir (ÇSGB UİS Raporu, 2015: 131).

İşletmelerde BT kullanımının artması sonucunda nitelikli iş gücü açığı duyulmaktadır ve gelecekte de Türkiye'nin büyüme hedeflerini karşılayabilmesi için robotik, bulut bilişim, büyük veri (metaveri), makineler arası iletişim, veri merkezleri, nano teknoloji, teletıp ve yapay zeka gibi alanlara yatırım yapılmalıdır (TBD Raporu, 2016). Bu sektörün aynı zamanda kendi işini kuran bilişimci girişimcilere de ihtiyacı gün geçtikçe artış göstermektedir.

Bilgisayar sahibi olma, internet kullanma, bilim, teknoloji ve Ar-Ge faaliyetleri yatırımlarının artış göstermesi bilişim girişimcisine olan ihtiyacı ortaya koyan göstergelerdir. (Orhan, 2010). Yeni teknolojilerin kaynağı insanın zihinsel emeği olarak adlandırılmaktadır ve toplumsal ve bireysel refah artışının sağlanması için teknolojiyi üreten ve kullanan nitelikli emek en önemli etkenlerdendir (Aydın, 2012). Bu nitelikli emek gücünün bilişim sektöründeki girişimciler olarak sektör içinde yerini zamanla arttırması beklenen bir durumdur.

Girişimcilik ve bilişim sektörü arasındaki ilişki incelendiğinde bilişim sektöründeki gelişmelerin girişimciliği desteklediği söylenebilir. Ayrıca meydana gelen teknolojik gelişmeler bilişim girişimcisine olan ihtiyacı da arttırmaktadır. Orhan (2010)'ın Türkiye'de büyüme için bilişim girişimcilerinin gerekliliğini açıkladığ 1 çalışmasında bilişim girişimcisi kavramı "bilgirişimci" olarak ele alınmıştır (Orhan, 2010). Bilgi teknolojilerinin kullanımının katkıları ile öne çıkan girişimci modeli "e-girişimci" olarak ta adlandırılabilmektedir. E-Girişimcilik kavramı yeni bir yenilikçi iş düşüncesini temel alarak yeni ekonomi ortamında bir girişime karşılık gelmektedir (Koçak, 2009). Bu konuda kullanılan bir başka kavram ise "internet girişimcisi" kavramıdır. İnternet girişimciliği kendi firsatını yaratıp ekip kurabilen, lider karakterli ve yaratıcı fikirlere sahip olup iş kurmayı isteme gibi girişimci özelliklerinin yanı sıra yazılımdan anlama, elektronik aletleri kullanabilme, internet ortamında satışlar yapmayı isteme gibi nitelikleri de üzerinde bulundurmayı gerektirmektedir (Yelkikalan vd., 2010). Bilişimci girişimcilerin nitelikleri arasında ayrıca yüksek düzeyli başarı güdüsüne sahip olma, hesaplı riskleri üstlenebiliyor olma, kişisel sorumluluk duygusuna sahip olup işlerini sonuçlandırabilme, girişiminde bulundukları işle ilgili bilgi tabanlı bir yapılanma kurabilme ve amaçları doğrultusunda bilişim sisteminden yararlanabilme gibi özellikler bulunmaktadır (Öğüt vd., 2006). BT sektörünü ve bu alandaki girişimciliği diğerlerinden ayıran farklar bulunmaktadır. Birincisi, bilişim girişimcilerinin diğer sektörlerde kullanımına gereksinimi duyulacak bilişim desteğini sağlamalarıdır. Bilişim girişimcileri sunacakları ürün ve 
hizmetler ile farklı ölçekteki işletmelerin gelişmesine destek sağlayacaktır. İkinci fark ise bu sektörde yapılacak yatırımların daha ağır sanayi yatırımlarına kıyasla daha düşük sermaye birikimleri ile yapılabiliyor olması ve katma değeri yüksek ürünlerin üretiliyor olmasıdır (Orhan, 2010).

\section{YÖNTEM}

Araştırmada katılımcılar 2016-2017 Eğitim Öğretim Yılı Bahar döneminde Balıkesir Üniversitesi Bilgisayar Mühendisliği Bölümünde eğitim gören öğrencilerdir. Diğer bölüm öğrencilerinin araştırmaya dahil olmaması araştırmanın sınırlılığıdır ve öğrenci sayısının düşük kalmasının bir nedenidir. Bilgisayar Mühendisliği bölümünün seçilme nedeni ise bilişim sektöründe çalışma potansiyellerinin yüksek görülmesidir. Bu çalışmada hazırlanan anket formu üç bölümden oluşmaktadır. Birinci bölümde demografik sorular sorulmuşken, ikinci bölümde öğrencilerin girişimci olma niyetleri ve girişimci özelliklerine ilişkin sorular sorulmuştur. Son bölümde ise bilişim konusuna yatkınlıklarını belirlemek için iki soru sorulmuştur. Sorular açık uçlu, çoktan seçmeli ve 5'li likert tipi özelliktedir. Çalışmada demografik özelliklere ilişkin ve kişilik özelliklerine ilişkin soruların bir kısmı genel bilgileri elde etmek için geliştirilmiştir. Soruların hazırlanmasında Liñán ve Chen (2009), in anket sorularından da (Entrepreneurial Intention Questionnaire, EIQ) yararlanılmıştır. $\mathrm{Bu}$ anketlerden yararlanılırken bazı sorularının kullanıldığı çalışmalar da dikkate alınmıştır (Liñán, Moriano ve Jaén, 2016; Liñán, Rodríguez-Cohard, RuedaCantuche, 2011; Liñán, F., Urbano, D., Guerrero, M., 2011 ). Ayrıca girişimcilik niyeti için bu ölçeği kullanarak yapılan çalışmalara Pretheeba (2014)'nın dört değişkeni ele aldığı, Şeşen ve Basım (2012)'ın beş boyutu incelediği çalışmalar da örnek verilebilir (Pretheeba, 2014; Şeşen ve Basım, 2012).

Veriler öncelikle tanımlayıcı istatistiksel analizler yapılarak değerlendirilmiştir. Yapılan Kolmogorov Simirnov testi sonuçlarına göre normallik varsayımı sağlanmadığından parametrik olmayan testlerin kullanılması uygun görülmüsstür. $\mathrm{Bu}$ nedenle öğrencilerin kariyer planları dikkate alınarak "girişimci olmak istemeleri”, “özel şirkette kariyer yapmak istemeleri” ve "kamuya ait birimlerde çalışmak istemeleri" durumlarının diğer değişkenler ile arasındaki ilişki Ki kare testleri ile analiz edilmiştir. Burada özellikle öğrencilerin kariyer planlarındaki farklılığın diğer değişkenler ile ilişkisi araştırılmıştır. Teorik değerlerde 5 ten küçük değerler bulunduğu için Monte Carlo Exact Pearson Ki Kare testleri tercih edilmiştir. Her bir grup anketi için güvenilirlik analizi yapılmıştır ancak öğrenci sayısının yeterli görülmemesi nedeniyle faktör ayrımı ya da ölçek değerlendirilmesi yapılmamış her bir görüş ve soru bağımsız olarak değerlendirilmiştir.

\section{BULGULAR}

Demografik Özellikler: Balıkesir Üniversitesi Bilgisayar Mühendisliği Bölümünde 2016-2017 Eğitim Öğretim Yılında kayıtlı olan 42 1.sınıf, 38 2. sınıf öğrencisi bulunmaktadır. Çalışmada ulaşılabilen 50 öğrencinin anket formu kullanılmıştır. Bu öğrencilerin otuzu 1. sınıfta, yirmisi 2. sınıfta okumakta olup yaş ortalamaları 19,56dır. Ayrıca, onbiri kadın, otuzdokuzu erkek öğrencidir. Aile 
üyeleri arasında onbirinin babasının, birinin kardeşinin kendi işi bulunmaktadır. Tablo 1'de verildiği gibi frekans analizi sonuçlarına göre büyük çoğunluğu girişimcilik eğitimi almamış olup eğitim almak istemektedirler ve bilişim sektöründeki değişmeleri takip eden, günlük hayatlarında bu bileşenleri kullanmaya yatkın kişilerdir.

Tablo 1: Özelliklere İlişkin Frekanslar

\begin{tabular}{|l|l|l|l|}
\hline Özellikler & Evet & Hayır & T \\
\hline Daha önce ya da şuan bir işte çalı̧̧ma durumu & 35 & 15 & 50 \\
\hline Girişimci bir kişiliğe sahip olduğunu düşünme durumu & 32 & 18 & 50 \\
\hline Ailesinin girişimciliğini destekleyeceğini düşünme durumu & 44 & 6 & 50 \\
\hline Girişimcilikle ilgili bir eğitim alma durumu & 4 & 46 & 50 \\
\hline Girişimcilikle ilgili bir eğitim almayanların alma isteği & 41 & 7 & 48 \\
\hline Finansman ihtiyacını karşıılayabileceğini düşünme durumu & 18 & 32 & 50 \\
\hline Girişimcilik teşvikleri ile ilgili bir araştırma yapma durumu & 13 & 37 & 50 \\
\hline Bilişim sektöründeki değişmeleri takip etme durumu & 48 & 2 & 50 \\
\hline $\begin{array}{l}\text { Günlük hayatında bilişim sektöründeki bileşenleri kullanmaya yatkın olma } \\
\text { durumu }\end{array}$ & 46 & 4 & 50 \\
\hline
\end{tabular}

Öğrencilerin kariyer planlarıyla demografik özellikleri ile ilgili ifadelerin ilişkisinin incelendiği ve Ho hipotezinin iki değişken arasında ilişki yoktur şeklinde kurulduğu bağımsızlık testine göre; 0,05 anlamlılık düzeyinde öğrencilerin kariyer planları ile girişimci bir kişiliğe sahip olduğunu düşünme durumu, girişimcilikle ilgili bir eğitim almayanların alma isteği, finansman ihtiyacını karşılayabileceğini düşünme durumu, girişimcilik teşvikleri ile ilgili bir araştırma yapma durumu, bilişim sektöründeki bileşenleri kullanmaya yatkın olma durumu arasında ilişki vardır sonucu elde edilmiştir. Elde edilen değerler Tablo 2'de verilmektedir.

Tablo 2: Özelliklere İlişkin Ki-kare Testleri

\begin{tabular}{|l|l|l|l|l|}
\hline Özellikler & $\mathrm{MC} \chi \mathrm{p} 2$ & $\mathrm{Sd}$. & $\mathrm{p}$ & 0,0 \\
\hline Cinsiyet & 1,776 & 2 &, 388 & $>$ \\
\hline Okuduğu sınıf & 1,328 & 2 &, 685 & $>$ \\
\hline Daha önce yada şuan bir işte çalışma durumu & 1,061 & 2 &, 593 & $>$ \\
\hline Girişimci bir kişiliğe sahip olduğunu düşünme durumu & 10,043 & 2 &, 003 & $<$ \\
\hline Ailesinin girişimciliğini destekleyeceğini düşünme durumu & 4,723 & 2 &, 109 & $>$ \\
\hline Girişimcilikle ilgili bir eğitim alma durumu & 2,031 & 2 &, 402 & $>$ \\
\hline Girişimcilikle ilgili bir eğitim almayanların alma isteği & 14,049 & 2 &, 016 & $<$ \\
\hline Finansman ihtiyacını karşlayabileceğini düşünme durumu & 9,649 & 2 &, 005 & $<$ \\
\hline Girişimcilik teşvikleri ile ilgili bir araştırma yapma durumu & 7,446 & 2 &, 031 & $<$ \\
\hline Aile üyeleri arasinda kendi işinin sahibi kişilerin olma durumu & 1,807 & 4 &, 911 & $>$ \\
\hline Biliş̧im sektöründeki değişmeleri takip etme durumu &, 864 & 2 & 1,000 & $>$ \\
\hline Günlük hayatında bilişimim sektöründeki bileşenleri kullanmaya yatkınlık & 6,713 & 2 &, 042 & $<$ \\
\hline
\end{tabular}

Girișimciliğe Yönelik Kişisel Tutum: Öğrencilerin Girișimciliğe yönelik kişisel tutum özelliklerine katılma düzeylerinin değerlendirilmesinde 5'li likert sorular kullanılmıştır ve güvenilirlik analizi Cronbach's Alpha değeri 0,921 olarak bulunmuştur. Öğrencilerin kariyer planlarıla girişimciliğe yönelik kişisel tutum özellikleri arasındaki ilişkinin incelendiği ve Ho hipotezinin iki değişken arasında ilişki yoktur şeklinde kurulduğu Ki kare testine göre; Ho hipotezi hiçbir madde için reddedilemez. Elde edilen değerler Tablo 3'te verilmektedir. 
Özlem. Kuvat / Bilişim Sektöründe Girişimcilik, Balıkesir Üniversitesi Bilgisayar Mühendisliği Öğrencilerinin Girişimcilik Ĕ̈ilim Ve Niyetleri Üzerine Bir Araştırma

Tablo 3: Girişimciliğe Yönelik Kişisel Tutum ve Ki-kare Testleri

\begin{tabular}{|c|c|c|c|c|}
\hline & $\mathrm{MC} \chi \mathrm{p} 2$ & Sd. & Sig. & 0,0 \\
\hline Girişimci olmak benim için dezavantajdan daha çok avantajlı sayılabilir. & 9,664 & 8 & 214 & $>$ \\
\hline Girişimci bir kariyere sahip olmak benim için çekicidir. & 12,234 & 8 &, 109 & $>$ \\
\hline Eğer firsat ve kaynaklara sahip olursam bir iş kurabilirim. & 17,380 & 8 & 058 & $>$ \\
\hline Girişimci olmak benim için başarı kriterlerinden biridir. & 4,783 & 8 & 789 & $>$ \\
\hline Farklı seçeneklere sahip olsam da girişimci olmayı tercih ederim. & 6,803 & 8 &, 577 & $>$ \\
\hline
\end{tabular}

5 görüş içerisinde katılma düzeyleri ortalamasında 4,18 puanıla en yüksek değeri "Eğer firsat ve kaynaklara sahip olursam bir iş kurabilirim." düşüncesi almıştır. Maddelere katılım düzeylerinin ortalaması Şekil 1'de verilmektedir. Bu maddeler arasında en düşük değeri alan görüşlerin ortalaması bile 3,5 puanın üzerindedir. Her bir maddeye ilişkin mod değerleri de sırasıyla 5,5,5,4,3 şeklinde gerçekleşmiş olup, ilk üç görüşe katılım çok yüksek düzeydedir.

Şekil 1: Girişimciliğe Yönelik Kişisel Tutum

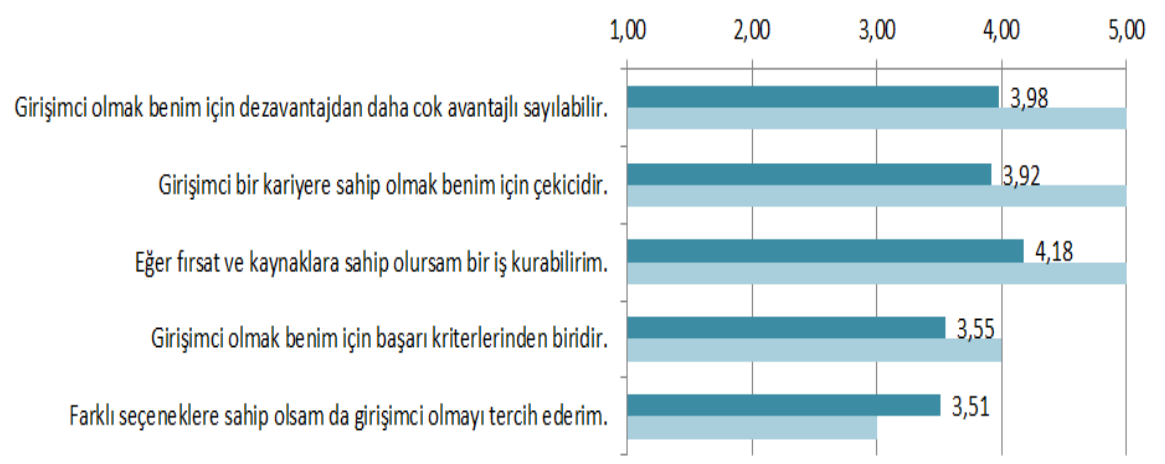

Girişimcilik Niyeti: Cronbach's Alpha değeri 0,936 olarak bulunmuştur. Tablo 4'te verilmekte olan 0,05 anlamlılık düzeyli $\mathrm{Ki}$ kare testine göre; öğrencilerin kariyer planları ile kendi işini kurmak ve sürdürmek için her türlü çabayı göstereceğini düşünme, gelecekte iş kurma konusunda kararlı olma, ciddi anlamda kendi işini kurmayı düşünme, bir gün kendi işini kurma konusunda ciddi niyetlerinin olması düşünceleri arasında ilişki vardır sonucu elde edilmiştir.

Tablo 4: Girişimcilik niyeti ve ki-kare testleri

\begin{tabular}{|l|l|l|l|l|}
\hline & MC $\chi \mathrm{p} 2$ & Sd. & Sig. & 0,05 \\
\hline Bir girişimci olarak her şeyi yapmaya hazırım. & 9,014 & 8 &, 332 & $>$ \\
\hline Benim profesyonel hedefim bir girişimci olmaktır. & 12,016 & 8 & 108 & $>$ \\
\hline Kendi işimi kurmak ve sürdürmek için her türlü çabayı göstereceğim. & $20,969 \mathrm{a}$ & 8 &, 006 & $<$ \\
\hline Gelecekte bir iş kurma konusunda kararlıyım. & $19,398 \mathrm{a}$ & 6 &, 001 & $<$ \\
\hline Ciddi anlamda kendi işimi kurmayı düşünüyorum. & $21,133 \mathrm{a}$ & 6 & 001 & $<$ \\
\hline Bir gün kendi işimi kurma konusunda ciddi niyetlerim var. & $22,089 \mathrm{a}$ & 6 &, 000 & $<$ \\
\hline
\end{tabular}

Öğrencilerin girişimcilik niyeti özelliklerine katılma düzeyleri değerlendirildiğinde 3,72 puanıyla en yüksek değeri "Bir gün kendi işimi kurma konusunda ciddi niyetlerim var." düşüncesi almıştır. Her bir maddeye ilişkin mod değerleri de sırasıyla 2,3,5,3,3,5 şeklinde gerçekleşmiş olup, üç ve beşinci görüşe katılım çok yüksek düzeydedir.

Maddelere katılım düzeylerinin ortalaması Şekil 2'de verilmektedir. 
Şekil 2: Girişimcilik Niyeti

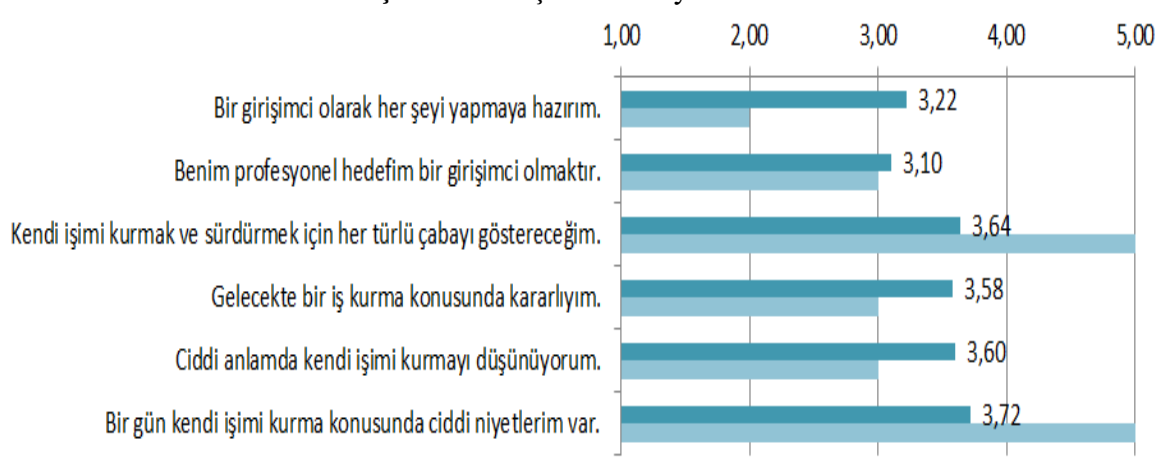

Girişimcilik Becerileri: Cronbach's Alpha değeri 0,878 olarak bulunmuştur. Tablo 5'te verildiği gibi $\mathrm{Ki}$ kare testine göre 0,05 anlamlılık düzeyinde; öğrencilerin kariyer planları ile firsatları fark edebilmek, yaratıcılık, yeni ürün ve hizmetlerin geliştirilmesi, profesyonel bağlantı ve ağ kurma becerisi gibi becerileri arasında ilişki vardır.

Tablo 5: Girișimcilik Becerileri ve Ki-kare Testleri

\begin{tabular}{|l|l|l|l|l|}
\hline & MC $\chi \mathrm{p} 2$ & Sd. & Sig. & 0,05 \\
\hline Frrsatları fark edebilmek & $18,075 \mathrm{a}$ & 8 &, 005 & $<$ \\
\hline Yaratıcılık & $13,066 \mathrm{a}$ & 6 & 029 & $<$ \\
\hline Problem çözme yeteneği & 9,644 & 8 &, 238 & $>$ \\
\hline Liderlik ve iletişim & $13,665 \mathrm{a}$ & 8 &, 111 & $>$ \\
\hline Yeni ürün ve hizmetlerin geliştirilmesi & $22,985 \mathrm{a}$ & 8 & 04 & $<$ \\
\hline Profesyonel bağlantı ve ağ kurma becerisi & $22,586 \mathrm{a}$ & 8 &, 004 & $<$ \\
\hline
\end{tabular}

Öğrencilerin girişimcilik becerileri özelliklerine katılma düzeyleri değerlendirildiğinde Şekil 3'te verildiği gibi 3,80 puanıyla "Yaratıcılık" özelliği öne geçmiştir. Maddelerin mod değerleri de sırasıyla 3,3,4,5,4,4 şeklinde gerçekleşmiş olup, "Liderlik ve iletişim" görüşüne katılım düzeyi çok yüksek frekans değerini taşımaktadır.

Şekil 3: Girişimcilik Becerileri

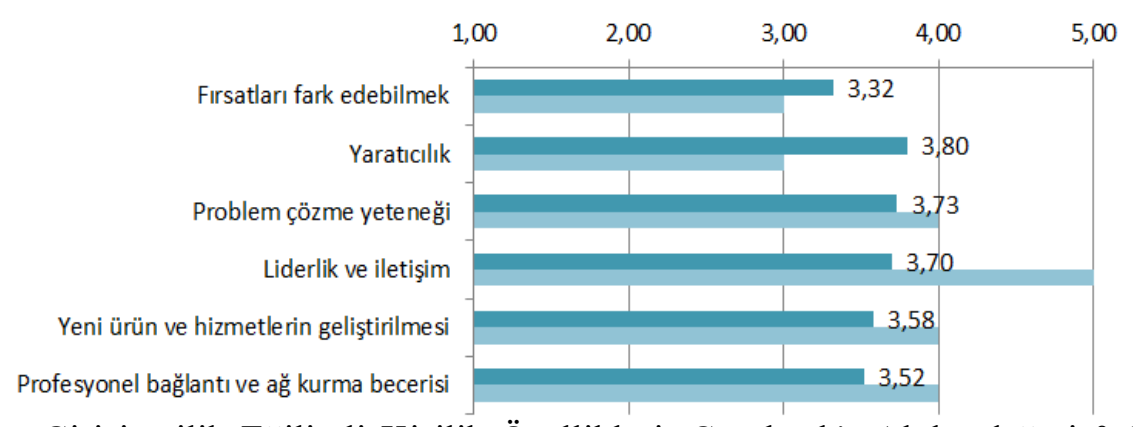

Girişimcilik Eğilimli Kişilik Özellikleri: Cronbach's Alpha değeri 0,695 olarak bulunmuştur. Tablo 6'da verilen Ki kare bağımsızlık testi sonucunda 0,05 anlamlılık düzeyinde öğrencilerin kariyer planları ile girişimcilik eğilimli kişilik özellikleri maddeleri arasında anlamlı bir ilişki olmadığı hipotezi reddedilememektedir. 
Özlem. Kuvat / Bilişim Sektöründe Girişimcilik, Balıkesir Üniversitesi Bilgisayar Mühendisliği Öğrencilerinin Girişimcilik Eğilim Ve Niyetleri Üzerine Bir Araştırma

Tablo 6: Girişimcilik Eğilimli Kişilik Özellikleri ve Ki-kare Testleri

\begin{tabular}{|l|l|l|l|l|}
\hline & $\mathrm{MC} \chi \mathrm{p} 2$ & Sd. & Sig. & 0,05 \\
\hline Başarı ihtiyacı hissederim. & 8,939 & 6 &, 186 & $>$ \\
\hline Kontrol odaklı bir insanım. & 12,993 & 8 &, 140 & $>$ \\
\hline Risk almaya ĕ̆ilimliyim. & 12,537 & 8 &, 108 & $>$ \\
\hline Belirsizliğe karşı toleranslıyım. & 2,273 & 8 &, 995 & $>$ \\
\hline Özgüven sahibiyim. & 12,246 & 8 &, 159 & $>$ \\
\hline Yeniliklere açı̆̆ım. & 8,225 & 8 &, 394 & $>$ \\
\hline
\end{tabular}

Girişimcilik eğilimli kişilik özellikleri içinde en yüksek ortalama değerine 4,26 puan ile yeniliklere açı olma özelliği sahiptir. Mod değerleri sırasıyla 4,4,4,3,4,5 şeklinde gerçekleşmiştir. Katılım düzeylerinin ortalaması Şekil 4'te verilmektedir.

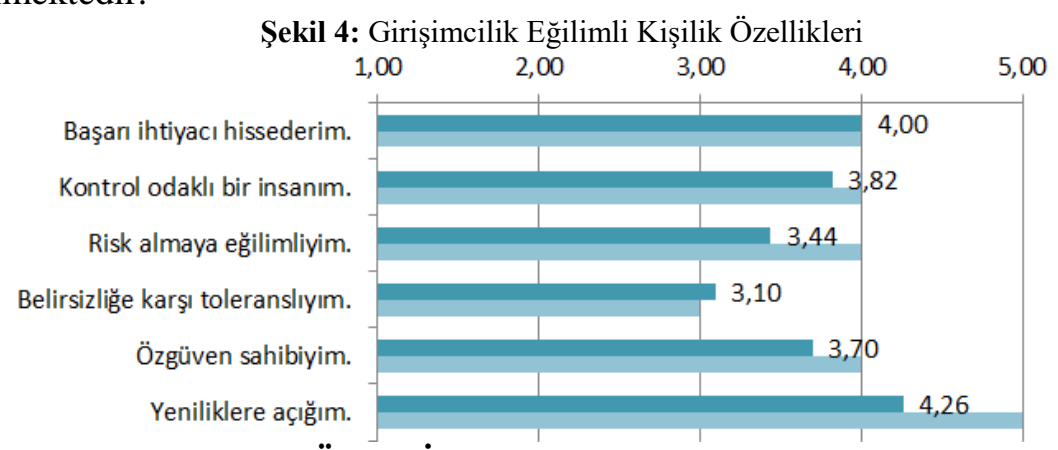

\section{SONUC VE ÖNERILER}

Bilişim sektöründe yaşanan değişim sürecindeki en önemli gereksinimlerden biri bu alanda girişimciliği artırmaktır. Bilişim girişimciliği hem girişimcilik kavramının hem de sürekli bir gelişme gösteren bilişim sektörünün ayrıntılı bileşenlerini içeren bir olgudur. Bu çalışmanın amacı bilişim girişimcisi olma potansiyeline sahip Bilgisayar Mühendisliği öğrencilerinin eğilim ve niyetlerinin sosyo-demografik özellikleriyle birlikte araştırılmasını sağlamak ve öğrencilerin ihtiyaçlarını saptamaktır. Çalışmanın sadece Balıkesir Üniversitesi'nde gerçekleştiriliyor olması sınırlılığını oluşturmaktadır ve başka üniversitelerde daha çok sayıda öğrenciye uygulanması hem geçerliliğini arttıracak hem de daha farklı analizlerin yapılmasına da olanak sağlayacaktır.

Öğrencilerin kariyer planları ile ilgili "girişimci olmak istemeleri”, "özel şirkette kariyer yapmak istemeleri" ve "kamuya ait birimlerde çalışmak istemeleri" durumlarının ki kare testleri sonuçlarına göre, girişimci kişiliğe sahip olduğunu düşünmesi, eğitim alma istekleri, finansman ihtiyacını karşılayabileceğini düşünmesi, araştırma yapması ve kendini bilişim sektörü bileşenlerini kullanmaya yatkın görmesi arasında anlamlı ilişki bulunmuştur. Cinsiyet, sınıf, ailede girişimci olması ve daha önce bir işte çalışma durumları ile ilgili anlamlı bir ilişski bulunamamıștır.

Öğrencilerinin girişimcilik niyetleri araştırıldığında elde edilen sonuçlara göre öğrencilerin girişimcilik konusunda en yüksek puan alan düşünceleri bir gün kendi işini kurmak, kendi işini kurup sürdürmek, ciddi anlamda işini kurmayı düşünmek ve gelecekte bir iş kurma konusunda kararlı olmak olmuştur. Bu durum 
öğrencilerin kendilerini şuan ve yakın gelecekte buna kendilerini hazır hissetmeseler de gelecekte hazır olduklarında iş kurma konusunda faaliyete geçebileceklerini göstermektedir. Öğrenciler, bir gün kendi işlerini kurma konusunda ciddi niyetlerinin bulunması ile firsat ve kaynaklara sahip olunursa iş kurabilecekleri düşüncelerine yüksek düzeyde katılmaktadırlar. Ayrıca büyük çoğunluğu; yaratıcılık, problem çözme yeteneği, liderlik ve iletişim becerilerine yüksek oranda sahip olduklarını düşünmektedirler ve kendilerini yeniliklere açık, başarı ihtiyacı hisseden ve kontrol odaklı kişiler olarak tanımlamışlardır. Belirsizliğe karşı toleranslarının olmaması düşünceleri ve risk alma konusundaki endişeleri de öğrencilik süreci boyunca edinecekleri birikimler, özel girişimcilik eğitimleri ve kendi işini kurmadan önce edinecekleri bir sürelik çalışma hayatı tecrübesi ile azaltılabilecektir.

Öğrencilerin \%96'sı bilişīim sektöründeki değişmeleri takip etmektedirler ve $\% 92$ 'si bileşenlerini kullanmaktadırlar. $\mathrm{Bu}$ durum bu bölümde okuyan öğrencilerin sektöre olan ilgisinin çok yüksek düzeyde olduğunu göstermektedir.

Öğrencilerin \%70'inin iş tecrübesi bulunmaktadır ve yine \%64'ü girişimci bir kişiliğe sahip olduğunu düşünmektedir. Bu oran değeri öğrencilerin çoğunun kendilerinin girişimci özelliklerine sahip olduğunu düşündüklerinin göstermektedir. $\% 88$ gibi yüksek bir oranda ailelerinin de kendilerini destekleyebileceklerini düşünmektedirler. \%92'si girişimcilikle ilgili bir eğitim almamıştır ve \%85'i bir eğitim almak istemektedirler. Öğrencilerin \%64'ü girişimci bir kişiliğe sahip olduğunu düşünse de ancak sadece \%36sı finansman ihtiyacını karşılayabileceğini düşünmektedir. Teşviklerle ilgili araştırma yapanların oranı da \%26 düzeyindedir. Elde edilen sonuçlara göre, öğrencilerin büyük çoğunun girişimci potansiyeline sahip olduğu ancak kendilerini girişimci olmaya hazır hissetmeleri için eğitimsel, finansal ve çevresel desteklere ihtiyaç duydukları söylenebilir. Bu ihtiyaçların karşılanması için farklı desteklerin planlı bir şekilde sağlanması teşvik edici olacaktır.

\section{KAYNAKÇA}

Abbas, Lutfiah N. (2013), "Engineering Students: What Factors Effects Their Entrepreneurial Intention", IOSR J. Hum. Soc. Sci, 15 (20), 35-40.

Arslantaş, Cem C. (2001), "Girişimcilikte Yaratıcılık Ve Yenilik”, İ.Ü. İşletme Fakültesi İşletme İktisadi Enstitüsü Yönetim Dergisi, 12(38),. 17-23.

Aydın, İsmail (2012), "Bilişim Sektörü Ve Türkiye'nin Sektördeki Potansiyeli”, International Journal of New Trends in Arts, Sports \& Science Education (IJTASE), 1 (1), 180-200.

Başer, Hakan ve Recep Büber (2012), "İş Kurma Amacı Olan Adayların Girişimcilik Özelliklerinin Ölçülmesi: Aydin İli’nde Bir Uygulama”. Sosyal Ve Beşeri Bilimler Dergisi, 4 (1), 136143.

Başol, Oğuz., Dursun Salih ve Serpil Aytaç (2011), "Kişiliğin Girişimcilik Niyeti Üzerine Etkisi: Üniversiteli Gençler Üzerine Bir Uygulama", “İş Güç" Endüstri İlişkileri ve İnsan Kaynakları Dergisi, 4 (13) ,7-22.

ÇSGB UİS Raporu, Bilişim Sektörü Mevcut Durum Raporu (Haziran 2015). www.uis.gov.tr/media/1312/bilisim_sektoru_ikinci_idk.pdf $(05,02,2017)$.

Denanyoh, Richard, Adjei Kwabena, and Gabrial E.Nyemekye (2015), "Factors That Impact On Entrepreneurial Intention Of Tertiary Students In Ghana", International Journal of Business and Social Research, 5 (3), 19-29. 
Gurel Eda, Altinay Levent and Roberto DANIELE (2010), "Tourism Students' Entrepreneurial Intentions. Annals Of Tourism Research", 37 (3), pp. 646-669.

İrmiş Ayşe ve Esin Barutçu (2012), "Öğrencilerin Kendilerini Girişimci Bir Kişiliğe Sahip Görmelerini Ve İş Kurma Niyetlerini Etkileyen Faktörler: Bir Alan Araştırması", Atatürk Üniversitesi İktisadi ve İdari Bilimler Dergisi, 26 (2), pp.1-25.

Karahoca, Dilek ve Adem Karahoca (1998), İşletmeciler, Mühendisler ve Yöneticiler İçin Yönetim Bilişim Sistemleri ve Uygulamaları, Beta Basım Yayım, İstanbul.

Koçak, Orhan (2009), "Bilgi Teknolojilerini Kullanan Yeni Girişimcilik Modelinin İş Yaratma Etkisi”, Sosyal Siyaset Konferanslar1 Dergisi, 57, 381-405.

Koh Hian. Chye (1996). "Testing Hypotheses Of Entrepreneurial Characteristics", Journal of Managerial Psychology, 11 (3), 12-25.

Liñán, Francisco, and Chen Yi-Wen (2009), "Development And Cross-Cultural Application Of A Specific Instrument To Measure Entrepreneurial Intentions", Entrepreneurship Theory and Practice, 33 (3),593-617.

Liñán, Francisco, Moriano Juan. A., and Jaén Inmaculada (2016), "Individualism And Entrepreneurship: Does The Pattern Depend On The Social Context?", International Small Business Journal, 34 (6), 760-776.

Liñán, Francisco, Rodríguez-Cohard Juan Carlos and Rueda-Cantuche José M. (2011), "Factors Affecting Entrepreneurial Intention Levels: A Role For Education", International Entrepreneurship And Management Journal, 7(2), 195-218.

Liñán, Francisco, Urbano, David, and Guerrero, Maribel (2011), "Regional Variations In Entrepreneurial Cognitions: Start-Up Intentions Of University Students In Spain”, Entrepreneurship and Regional Development, 23 (3-4), 187-215.

Orhan, Kamil (2010), “Türkiye'de Büyüme İçin Olası Bir Anahtar: Bilgirişimci”, Sosyoekonomi, 13 (13), 30-58.

Öğüt, Adem, Şendoğdu, Aslan ve Nahit Yılmaz (2006), Bilişimci Girişimcilik Tipolojisi Açısından Bilgi Yönetiminin İlkeleri, Kırgızistan-Türkiye Manas Üniversitesi, Uluslararası Girişimcilik Kongresi, Kırgızistan-Türkiye Manas Üniversitesi Yayınları: 86 , 25-27 Mayıs 2006, Bişkek.

Özdemir, Lütfiye (2015), "Kırgızistan-Türkiye Manas Üniversitesi Öğrencilerinin Girişimcilik Eğilimlerinin Sosyo-Demografik Özellikler Açısından Değerlendirilmesi”, Süleyman Demirel Üniversitesi İktisadi Ve İdari Bilimler Fakültesi Dergisi, 20(1),617-626.

Öztürk, Yunus Emre, Köksal Onur ve Ramazan Kıraç (2014). "Sağlık Yönetimi Bölümü Öğrencilerine Yönelik Girişimcilik Ölçeğinin Geliştirilmesi”, Journal of Human Sciences, 11 (2), 582-597.

Pretheeba, Pratheesh (2014), "Predicting Entrepreneurial Intention Among Business And Engineering Students İn Sri Lanka", Ruhuna Journal of Management and Finance, 1 (1), pp.25-36.

Sánchez, Jose. C. and Licciardello ORAZİO (2012), "Gender Differences And Attitudes In Entrepreneurial Intentions: The Role Of Career Choice", Journal of Women's Entrepreneurship and Education, 1 (2), 7-27.

Sarıtaş, Ahmet ve Gülhan DURAN (2017), "Üniversite Öğrencilerinin Girişimcilik Eğilimlerinin Tespitine İlişkin Bir Araştırma", Muş Alpaslan Üniversitesi Sosyal Bilimler Dergisi, 5 (1), $147-164$.

Shekhawat, Himanshu., TAK Preeti, and Savita Panwar (2012), "Entrepreneurial Intentions Of Management Students: An Empirical Analysis", Journal Of Entrepreneurship And Management, 1 (3), 15-23.

Solmaz, Seyit. A., Aksoy Özlem, Sengül Serkan ve Mehmet Sarışık (2014), "Üniversite Öğrencilerinin Girişimci Kişilik Özelliklerinin Belirlenmesi: Turizm Lisans Ve Ön Lisans Öğrencileri Üzerine Bir Alan Araştırması", KMÜ Sosyal Ve Ekonomik Araştırmalar Dergisi, 16 (26), 41-55.

Şeşen, Harun ve Nejat Basım (2012), "Demografik Faktörler Ve Kişiliğin Girişimcilik Niyetine Etkisi: Spor Bilimleri Alanında Öğrenim Gören Üniversite Öğrencileri Üzerine Bir Araştırma", Ege Akademik Bakış, 12, 21-28. 
Turker, Duygu and Sönmez Selçuk Senem (2009), "Which Factors Affect Entrepreneurial Intention Of University Students?", Journal of European Industrial Training, 33 (2), 142-159.

Türkiye Bilişim Derneği, (2016), TBD 2015 Değerlendirme Raporu, Ocak 2016, Rapor Sayısı:10. Uygun, Mutlu, Mete Sinan ve Ebru Güner (2012), "Genç Girişimci Adayların Girişimcilik Eğilimi Ve Girişimcilik Özellikleri Arasındaki İlişkiler", Organizasyon ve Yönetim Bilimleri Dergisi, 4 (2), 145-156.

Yelkikalan, Nazan, Akatay Ayten, ve Emel Altın (2010), "Yeni Girişimcilik Modeli Ve Yeni Nesil Girişimci Profili: İnternet Girişimciliği Ve Y, M, Z Kuşağı Girişimcisi”, Selçuk Üniversitesi İIBF Sosyal ve Ekonomik Araştırmalar Dergisi, 1 (20), 489-506.

\section{SUMMARY}

Entrepreneurship; it is an activity that increases employment opportunities in a country economy and thus contributes to economic wealth.

As a result of the technological advances in the world; various opportunities for entrepreneurs in Turkey has increased. In evaluating these opportunities; people who are entrepreneurial and who are in the industry at the same time are advantageous. Computer Engineers are also people with high level of employment within the sector. It is important that they have entrepreneurial qualifications and prepare themselves in this respect. Also; It is important for the IT field to determine and evaluate the characteristics of individuals who have entrepreneurial qualifications for the needs of the sector and who think about starting their own business.

Although the speed and importance of the information processing process in the world until the end of the 20th century is not sufficiently understood, today information is constantly shared. The emergence of the global economy, the transformation of industrial economies and the processes of change in enterprises are very effective in this. As a result of these changes and transformations, the IT revolution has begun and this process is still continuing.

Computer Engineering students have the potential to work in the IT industry in the future. Determining their inclination to be an entrepreneur will be important for providing support to increase their success. There are many studies in the literature on the determination of entrepreneurship trends and intentions of university students. On the other hand, deficiencies in the evaluation of trends and intentions of IT sector students and computer engineering students were effective in determining the subject of this study. The aim of the study is to investigate the tendencies and tendencies of Computer Engineering students to be entrepreneurs. The application was carried out with the participation of Balikesir University Computer Engineering students. Questionnaire method was used in data collection phase. The results of the survey were analyzed and the results obtained were presented.

According to the results obtained; Students' career plans; There is a significant relationship between thinking to have entrepreneurial personality, willingness to receive education, thinking that it can meet the need for financing, doing research and using self-knowledge components. There was no significant relationship between gender, class, family entrepreneurship and previous employment status. When the entrepreneurship intentions of their students are 
investigated, the highest scoring thoughts about entrepreneurship; One day was to start his own business, to start his own business, to seriously think about setting up his business and to be determined to start a business in the future. Students, they can one day they will have the serious intention to set up a business with the opportunities and resources available on establishing their own businesses are involved at high levels. Also the vast majority; They think that they have a high rate of creativity, problem solving ability, leadership and communication skills. They have defined themselves as innovators, people who feel the need for success and control-oriented people. Thoughts of lack of tolerance towards uncertainty and their concerns about risk taking can be reduced by the accumulations they will acquire during the student period. Private entrepreneurship trainings and a working life experience that they will acquire before starting their own business can be important. 